\title{
Nine-residue peptide self-assembles in the presence of silver to produce a self-healing, cytocompatible, antimicrobial hydrogel
}

Areetha D'Souza ${ }^{1}$, Jennifer H. Yoon ${ }^{1}$, Henry Beaman², Pallavi Gosavi ${ }^{1}$, Zsofia LengyelZhand ${ }^{1}$, Alex Sternisha ${ }^{1}$, Garrick Centola ${ }^{1}$, Liam R. Marshall ${ }^{1}$, Matthew D. Wehrman ${ }^{3}$, Kelly M. Schultz ${ }^{3}$, Mary Beth Monroe ${ }^{2}$, Olga V. Makhlynets ${ }^{1 *}$

${ }^{1}$ Department of Chemistry, Syracuse University, 111 College Place, Syracuse, NY 13244 USA; ${ }^{2}$ Biomedical \& Chemical Engineering, Syracuse University, 318 Bowne Hall, Syracuse, NY 13244 USA; ${ }^{3}$ Chemical and Biomolecular Engineering, Lehigh University, lacocca Hall, 111 Research Drive, Bethlehem, PA 18015

Corresponding author: ovmakhly@syr.edu 


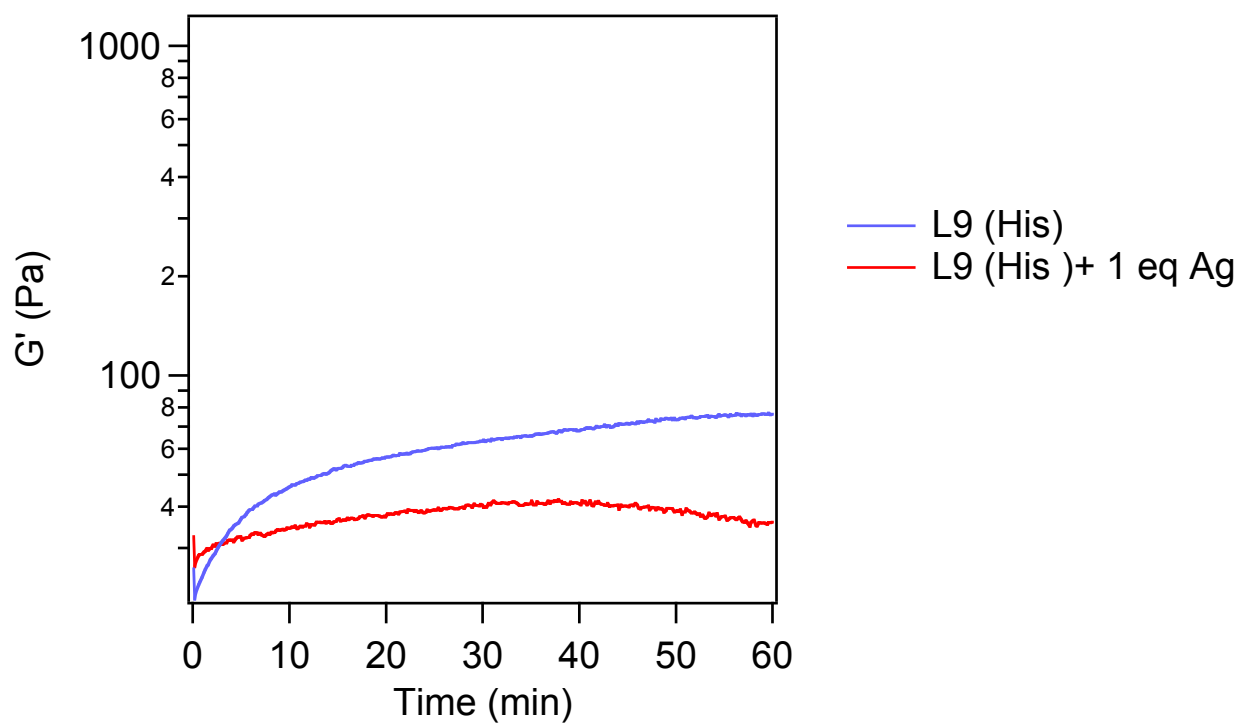

Figure S1. Evolution of storage modulus for hydrogels made by mixing L9(His) peptide (1wt\%) and 1 eq of $\mathrm{AgNO}_{3}$.

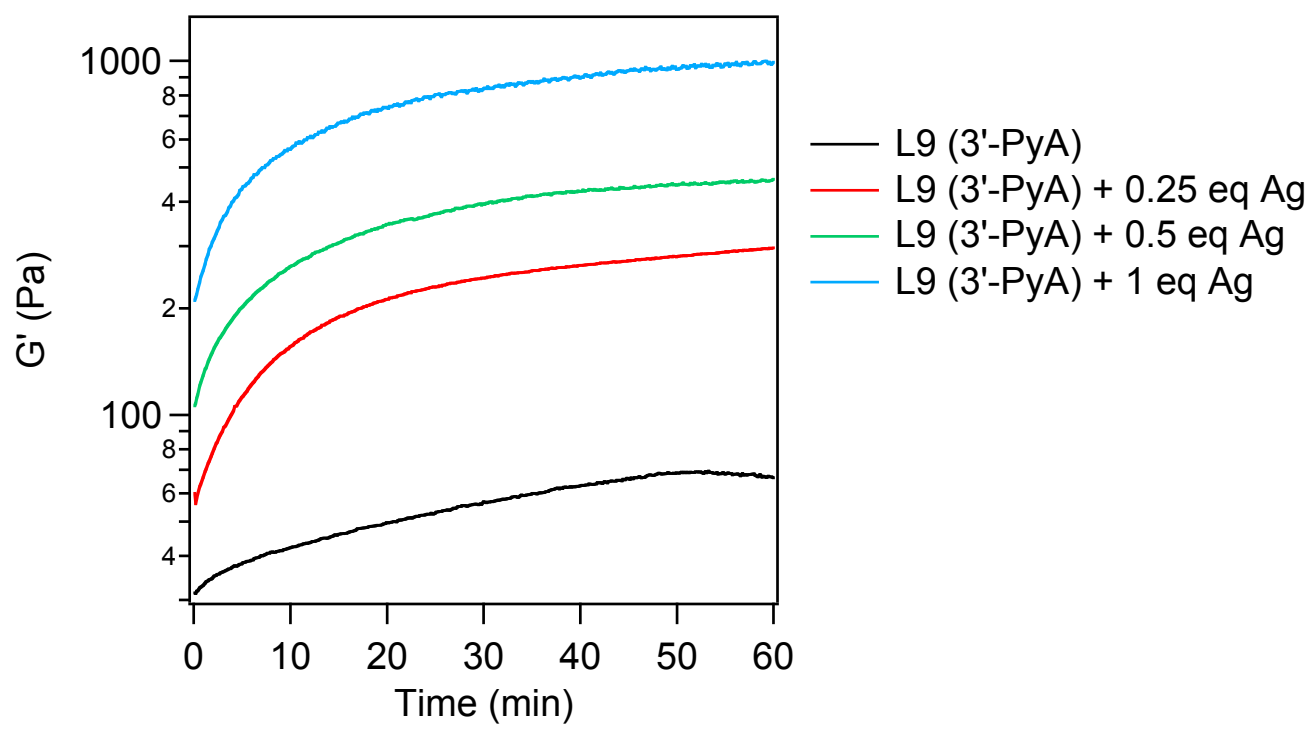

Figure S2. Evolution of storage modulus for hydrogels made by mixing L9 (3'-PyA) peptide (1wt \%) and variable amount of $\mathrm{AgNO}_{3}(0-1 \mathrm{eq})$. 


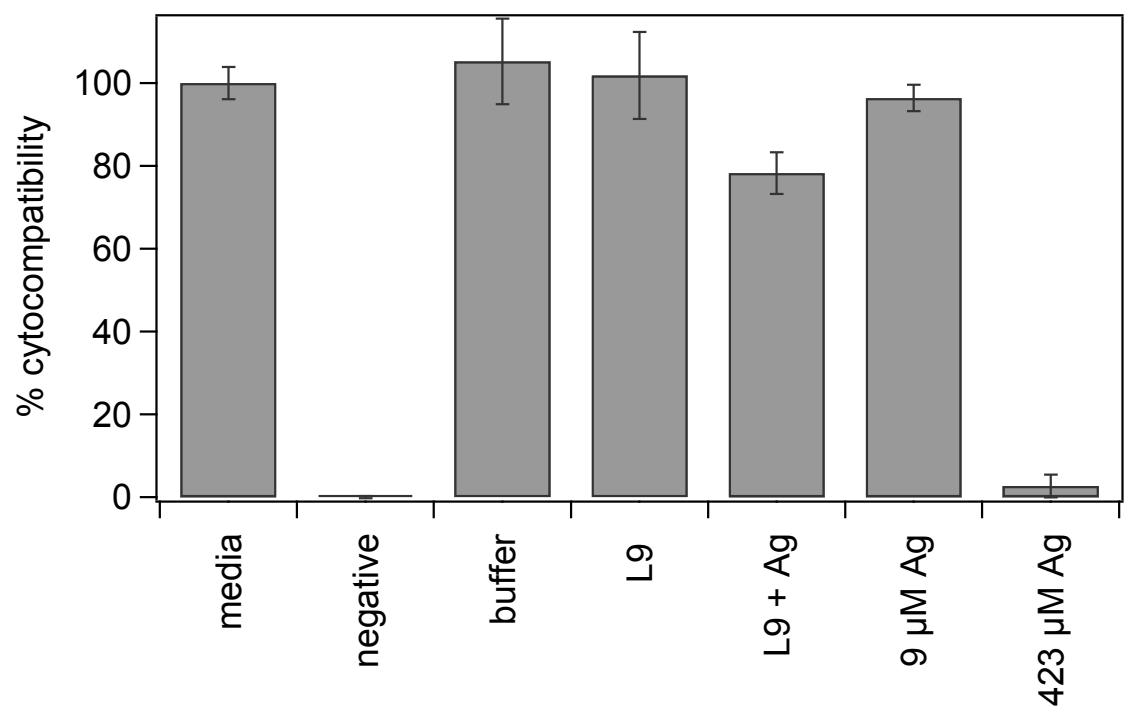

Figure S3. Cytocompatibility as measured by neutral red uptake (NRU) assay. Extracts were prepared by incubation of the media with various samples for 72 hours. Mouse 3T3 fibroblasts were treated with these extracts and cytocompatibility was measured. Negative control contained $6 \%$ hydrogen peroxide. "L9 + Ag" sample corresponds to an extract in contact with hydrogel prepared from $3.75 \mathrm{mM}$ L9 $(0.5 \mathrm{wt} \%), 1.88 \mathrm{mM} \mathrm{Ag}(0.5$ eq) and $7.5 \mathrm{mM} \mathrm{NaNO}$ (2 eq) in buffer (50 mM HEPES, pH 8.0). "L9" hydrogel was prepared from L9 $(0.5 \mathrm{wt} \%)$ and 2.5 eq of $\mathrm{NaNO}_{3}$. Samples containing just variable silver concentration ("9 $\mu \mathrm{M} \mathrm{Ag"} \mathrm{and} \mathrm{"423} \mu \mathrm{M} \mathrm{Ag")} \mathrm{were} \mathrm{prepared} \mathrm{by} \mathrm{adding} \mathrm{AgNO}_{3}$ to the media and these samples were incubated for 72 hours before treatment of fibroblast cells. 


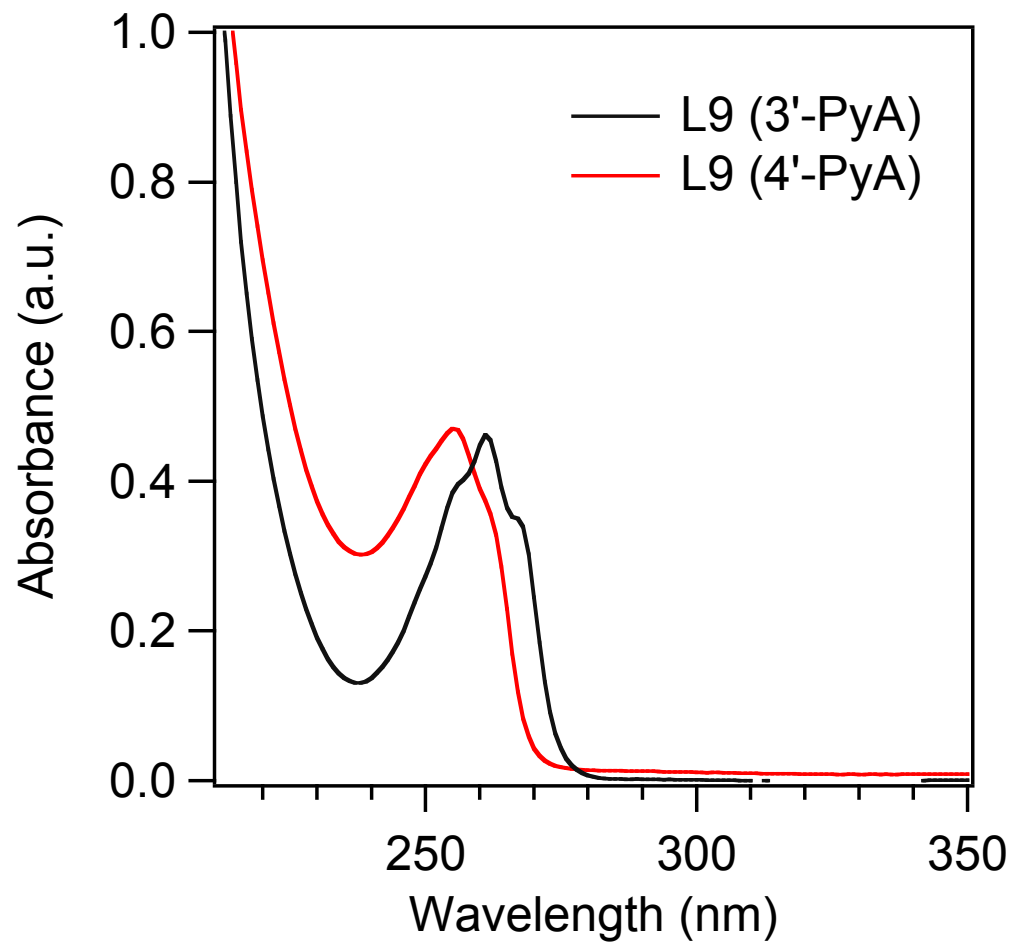

Figure S4. UV-vis spectra of L9 peptides with 3'-PyA and 4'-PyA in water. 